\title{
Polyethylene Glycol-Coated Gold Nanoparticles as DNA and Atorvastatin Delivery Systems and Cytotoxicity Evaluation
}

\author{
José Alberto Zamora-Justo ${ }^{1 D},{ }^{1}$ Paulina Abrica-González, ${ }^{1}$ \\ Guillermo Rocael Vázquez-Martínez, ${ }^{1}$ Alejandro Muñoz-Diosdado, ${ }^{1}$ \\ José Abraham Balderas-López, ${ }^{1}$ and Miguel Ibáñez-Hernández ${ }^{2}$ \\ ${ }^{1}$ Instituto Politécnico Nacional, Unidad Profesional Interdisciplinaria de Biotecnología, Department of Basic Sciences, \\ Mexico City 07340, Mexico \\ ${ }^{2}$ Instituto Politécnico Nacional, Escuela Nacional de Ciencias Biológicas, Department of Biochemistry, Mexico City 11340, Mexico \\ Correspondence should be addressed to José Alberto Zamora-Justo; zamora.justo@outlook.com
}

Received 19 May 2019; Accepted 19 August 2019; Published 13 October 2019

Academic Editor: Andrew R. Barron

Copyright ( 2019 José Alberto Zamora-Justo et al. This is an open access article distributed under the Creative Commons Attribution License, which permits unrestricted use, distribution, and reproduction in any medium, provided the original work is properly cited.

\begin{abstract}
The application of nanoscience and nanotechnology in medicine has been useful in the diagnosis, monitoring, and treatment of many diseases. Gold nanoparticles are commonly used for medical imaging studies, biosensors, drug delivery systems, and gene therapy. It has been reported that nanoparticles coated with specific polymers improve the biocompatibility and stability and decrease the cytotoxicity of the nanoparticles. In this work, we performed transfection studies of gold nanoparticles coated with polyethylene glycol, synthetized by two different methods, in a human embryonic kidney cell culture (HEK 293), by using plasmids pSV- $\beta$-Gal and pIRES2-EGFP. In addition, we also evaluated the cell uptake of a fluorescent drug (atorvastatin) using the synthetized gold nanoparticles as carriers. Furthermore, the study of cell viability after the interaction between these cells and the nanoparticles was performed. It was shown that the polyethylene glycol-coated gold nanoparticles presented transfection efficiency and cell uptake greater than $45 \%$ in each case. These results suggest that the synthetized gold nanoparticles coated with polyethylene glycol could be used successfully and safely as DNA and drug delivery systems.
\end{abstract}

\section{Introduction}

Currently, nanomedicine is a field that has great interest in the scientific community [1], since it has found application in many areas of science such as medical imaging [2], tumor targeting [3], drug delivery [4, 5], and biosensors [6], among others. Particularly, nanoparticles have been widely studied for medical purposes; however, the main problem consists in finding the materials with optimal biocompatibility [7]. It has been found that gold nanoparticles (AuNPs) are one of the most innocuous nanoparticles for living organisms [8], and it is suspected that most of the nanoparticles enter into the cells by endocytosis [9]. Nonetheless, the cytotoxicity of most of AuNPs depends on several parameters such as size, tissue distribution, penetration capacity, tissue absorption, and cell types [10].

It has been reported that AuNPs with sizes between 4 and $5 \mathrm{~nm}$ may have toxicity due to penetration into the nuclear compartment where they could bind to DNA; for instance, the $1.4 \mathrm{~nm}$ AuNPs have a strong toxic potential on DNA [11]. On the other hand, gold nanoparticles with sizes of 18 and $20 \mathrm{~nm}$ show greater cell viability in some kinds of cell cultures [11].

Chithrani et al. [12] showed that the diameter of gold nanoparticles influences the cellular uptake in a HELA cell culture; as the size of the AuNPs increases (from 14 to $50 \mathrm{~nm}$ ), the concentration of the nanoparticles into the cell is greater, the maximum cellular uptake occurs at the size 
of $50 \mathrm{~nm}$, and subsequently, there is a decrease in the cellular uptake (sizes from 70 to $100 \mathrm{~nm}$ ). In addition, several researches have reported an improvement in the cellular uptake of gold nanoparticles by using a biopolymer coating [13].

Nanoparticle surface coated with polymers can regulate and improve their stability, solubility, and focalization [14]. In vivo studies suggest that nanoparticles without covering can agglomerate due to different substances present in biological fluids which could cause an obstruction of small capillaries. Some conditions that the polymer must fulfill are as follows: it must be biocompatible, it must not generate an immune response, and it must be biodegradable by the organism [15].

Hereby, gold nanoparticles have potential applications as a gene delivery vehicle with multiple purposes [13]. The transfection efficiency of a plasmid is the rate between the number of cells which express the genetic information inserted by a vehicle and the total number of cells. Currently, there has been a search for nonviral gene vehicles which present the best characteristics, high transfection efficiency, and low cytotoxicity [16]. The nonviral gene vehicles commonly used for transfection studies are organic molecules; for instance, cationic liposomes have acceptable transfection efficiency and high cell viability [17]. However, gold nanoparticles have been also considered for this purpose [18].

Furthermore, gold nanoparticles have been used as drug delivery systems due to their easy functionalization with a drug which uses the nanoparticles as the carrier [19]. In some cases, the bond produced between the nanoparticle and the drug can be easily hydrolyzed by the cell enzymes and release the drug into the cell.

In vitro viability assays are used to measure the proportion of living cells after a potentially traumatic procedure; they are dependent on the alteration of the permeability of the membrane that is determined by the incorporation of agents that are normally impermeable, [20]; for instance, the trypan blue method is based on a blue dye which stains the dead cells due to the damage to the membrane permeability.

In this work, the transfection study of plasmids pSV- $\beta$ Gal and pIRES2-EGFP by using gold nanoparticles coated with polyethylene glycol (PEG) as a gene delivery vehicle was performed. The gold nanoparticles were synthetized by chemical reduction at two sizes, 20 and $40 \mathrm{~nm}$. The transfection study was evaluated by means of a cell culture of embryonic kidney cells (HEK 293). In addition, the cell uptake of the PEGylated gold nanoparticles loaded with a fluorescent drug, the atorvastatin which is a drug for cholesterol synthesis inhibition, was evaluated. Furthermore, the viability study of the cells incubated with the PEGylated gold nanoparticles was performed by a trypan blue technique.

\section{Methods}

The synthesis of gold nanoparticles was performed by a chemical reduction method [21] using sodium borohydride and cetyltrimethylammonium bromide $(\mathrm{CTAB})$ as reducing agents $[22,23]$. All glassware was washed with aqua regia $\left(150 \mathrm{~mL}\right.$ of $\mathrm{HCl}$ and $50 \mathrm{~mL}$ of $\mathrm{HNO}_{3}$ ) and rinsed with MiliQ water before use. In addition, all AuNPs were synthetized by using a $25 \mathrm{mM}$ stock solution of gold (III) chloride hydrate (Sigma-Aldrich, USA).

2.1. Synthesis of $20 \mathrm{~nm}$ Gold Nanoparticles. Synthesis of $20 \mathrm{~nm}$ gold nanoparticles was performed by the seed growth method [22]. The seed solution was prepared with $200 \mu \mathrm{L}$ of the gold stock solution $(25 \mathrm{mM})$ dissolved in $18.7 \mathrm{~mL}$ of MiliQ water in a flask with slight stirring, $600 \mu \mathrm{L}$ of $100 \mathrm{mM}$ sodium borohydride solution and $500 \mu \mathrm{L}$ of $10 \mathrm{mM}$ sodium citrate solution were added, the stirring continued during one hour at room temperature, and color change from light yellow to light pink was observed. The growth solution was prepared with $625 \mu \mathrm{L}$ of the gold stock solution and $100 \mu \mathrm{L}$ of $100 \mathrm{mM}$ CTAB solution (Sigma-Aldrich, USA), and the volume of the mixture was fixed up to $250 \mathrm{~mL}$ with MiliQ water. The growth solution was added to the seed slowly in stirring during 2 hours at room temperature. The nanoparticles were purified by centrifugation at 5,000 $\mathrm{g}$ for 10 minutes, the supernatant was removed, and the volume was completed with fresh MiliQ water in order to remove the unreacted CTAB. The synthetized gold nanoparticles were stored at $4^{\circ} \mathrm{C}$.

2.2. Synthesis of $40 \mathrm{~nm}$ Gold Nanoparticles. For the synthesis of $40 \mathrm{~nm}$ gold nanoparticles, $500 \mu \mathrm{L}$ of the gold stock solution $(25 \mathrm{mM})$ was dissolved in $50 \mathrm{~mL}$ of water in a flask with slight stirring and a solution of $30 \mathrm{mg}$ of sodium borohydride (Fluka Analytical, USA) in $10 \mathrm{~mL}$ of cold water that was added by stirring; the stirring continued during 5 hours at room temperature, until color change from light yellow to light pink was observed. In addition, $1 \mathrm{~mL}$ of an aqueous solution of sodium citrate (Sigma-Aldrich, USA) at $1 \mathrm{mM}$ was added to the mixture and kept in stirring for 30 minutes more; it worked as a stabilizing agent. The purification was carried out by centrifugation at 5,000 $\mathrm{g}$ for 10 minutes, and the supernatant was replaced with MiliQ water. Finally, the synthetized gold nanoparticles were stored at $4^{\circ} \mathrm{C}$.

2.3. Synthesis of the AuNP-PEG Nanoparticles. The synthetized gold nanoparticles were functionalized with polyethylene glycol ( $\mathrm{SH}-\mathrm{PEG}-\mathrm{NH}_{2}, \mathrm{MW} 2 \mathrm{kDa}$, Dendritech Inc., USA) following the method reported by Khutale and Casey [24], where the thiol group of the polymer binds to the gold nanoparticles: in a $70 \mathrm{~mL}$ of $30 \mu \mathrm{M}$ of AuNP solution, $1 \mathrm{~mL}$ of $1 \mu \mathrm{M}$ SH-PEG- $\mathrm{NH}_{2}$ solution was added; this mixture was stirred for $15 \mathrm{~min}$ at room temperature. Subsequently, the solution was stored at $4^{\circ} \mathrm{C}$ overnight to react.

2.4. Nanoparticle Characterization. In metal nanostructures, a phenomenon known as surface plasmon resonance (SPR) can be observed; it is shown in the spectrum as a strong absorption band and corresponds to the wavelengths in which the electrons of nanoparticles vibrate due to the light absorption. This band is characteristic of gold nanoparticles in regions around 520-540 $\mathrm{nm}$ [25]. The optical absorption spectrum of the sample was measured from 400 to $700 \mathrm{~nm}$ in a Perkin Elmer spectrometer (Lambda 25) and using MiliQ water as a blank. Furthermore, a stabilizing test of the coated and uncoated gold nanoparticles was performed evaluating the differences between absorption spectra of the particles at different $\mathrm{pH}$. The $\mathrm{pH}$ was adjusted by adding $0.2 \mathrm{M}$ citric 


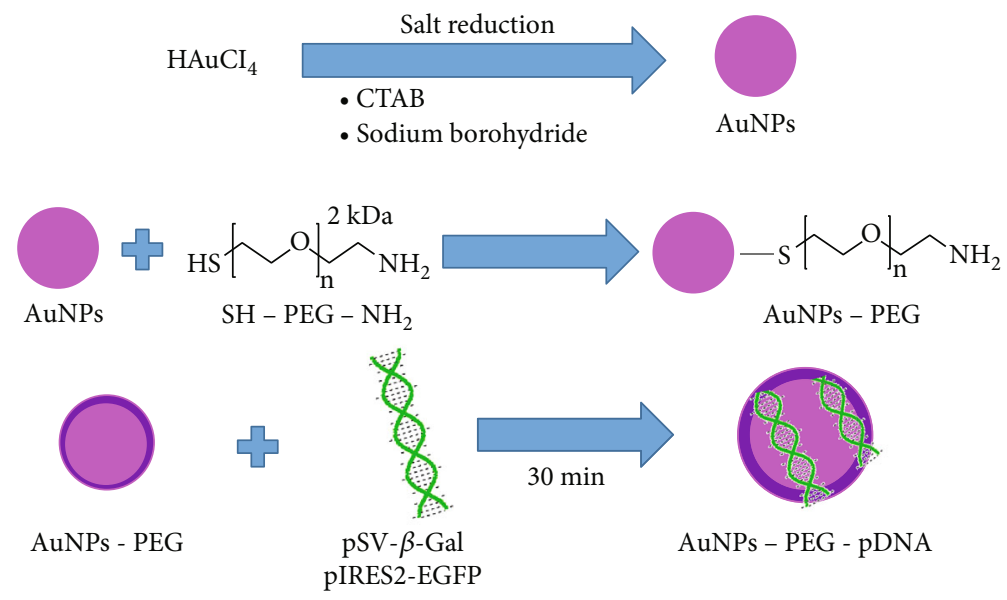

Figure 1: Scheme of the nanocomposites synthetized by two different methods. The $\mathrm{HAuCl}_{4}$ salt is reduced by different agents in order to obtain gold nanoparticles with two sizes, $20 \mathrm{~nm}$ (CTAB) and $40 \mathrm{~nm}$ (sodium borohydride). After, the surface gold atoms bind to the thiol group of the PEG; the exposed amino group interacts with the negative charges of the pDNA.

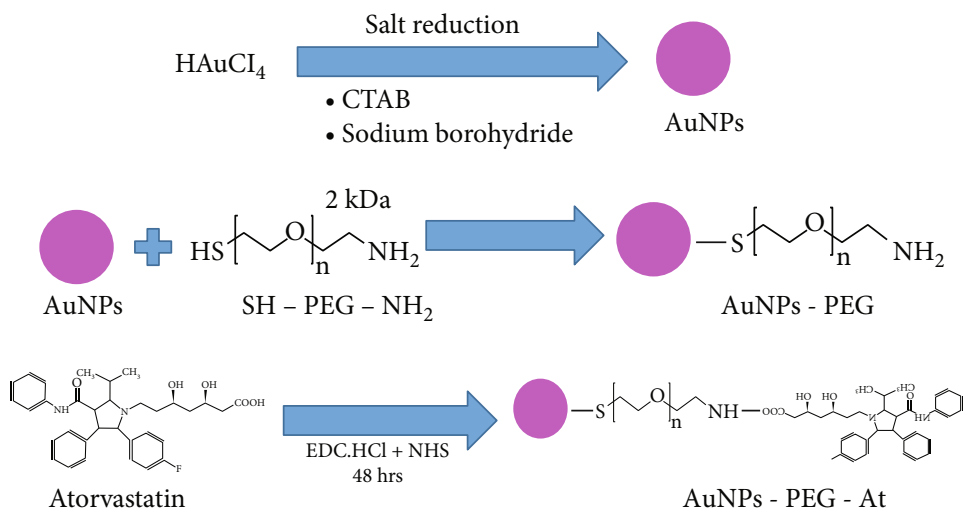

Figure 2: Scheme of the nanocomposites synthetized by two different methods. The $\mathrm{HAuCl}_{4}$ salt is reduced by different agents in order to obtain gold nanoparticles with two sizes, $20 \mathrm{~nm}$ (CTAB) and $40 \mathrm{~nm}$ (sodium borohydride). After, the surface gold atoms bind to the thiol group of the PEG; the exposed amino group reacts with the activated carboxyl group of the atorvastatin producing an amide bound.

acid and $0.1 \mathrm{M}$ sodium hydroxide (Sigma-Aldrich, USA) solutions, respectively.

The shape and size distribution of the synthesized nanoparticles were characterized with a JEOL 1011 Electron Transmission Microscope (TEM) by placing $20 \mu \mathrm{L}$ of the sample on a grid with a formvar membrane and letting it dry at room temperature.

In addition, the characterization of the synthetized gold nanoparticles $Z$ potential and hydrodynamic diameter was performed by using Zetasizer Malvern Nano Z (Worcestershire, United Kingdom).

2.5. Synthesis of the AuNP-PEG-pDNA. The pSV- $\beta-G a l$ was isolated from Escherichia coli DH5 bacteria strain; the purification of the plasmid was performed by means of the alkaline lysis method using the kit Ultra Clean $\mathrm{MoBio}^{\circledR}$ (California, USA). Different quantities of pDNA $(100,200,300$, and $400 \mathrm{ng}$ ) were added to the synthesized nanocomposites for 30 minutes, and this interaction was evaluated with electrophoresis in agarose gel $0.8 \%$ at $90 \mathrm{~V}$ by 40 minutes.

Gold nanocomplex were formed due to the pDNA bound to the PEGylated gold nanoparticles by means of charge interaction between the amine group of the SH-PEG-NH and the negative charges of the phosphates on the DNA helix. The scheme of the synthesis of AuNP-PEG-pDNA can be observed in Figure 1.

2.6. Synthesis of the AuNP-PEG-At. In order to activate the carboxyl group of atorvastatin (Sigma-Aldrich, USA), $1 \mathrm{mg}$ of NHS (N-hydroxysuccinimide, $\mathrm{C}_{4} \mathrm{H}_{5} \mathrm{NO}_{3}$ ) and $1.78 \mathrm{mg}$ of EDC-HCl (N-(3-dimethylaminopropyl)- $\mathrm{N}^{\prime}$-ethylcarbodiimide hydrochloride, $\mathrm{C}_{8} \mathrm{H}_{17} \mathrm{~N}_{3} \cdot \mathrm{HCl}$ ) were added to $2 \mathrm{~mL}$ of a solution of atorvastatin $(1 \mathrm{mg} / \mathrm{mL})$; this mixture was stirred for 30 minutes. Subsequently, the activated atorvastatin was added to $50 \mathrm{~mL}$ of the AuNP-PEG $14 \mu \mathrm{M}$. The synthesis scheme of the AuNP-PEG-atorvastatin is shown in Figure 2.

2.7. Cellular Transfection Study. The gold nanoparticles coated with PEG and the pDNA (Au-PEG-pDNA) were incubated with human embryonic kidney cells (HEK 293 cell culture) in order to evaluate the transfection efficiency. The HEK 293 cells were cultured in Dulbecco's modified Eagle's medium (DMEM, Sigma-Aldrich, USA) in an atmosphere of $5 \% \mathrm{CO}_{2}$ at $37^{\circ} \mathrm{C}$; the cells were incubated in 96 well plates 
where the transfection was performed with $90 \%$ confluence (12,000 cells per well). $20 \mu \mathrm{L}$ of gold nanocomplex and $30 \mu \mathrm{L}$ of medium were added to each well by 2 hours; subsequently, the volume was fixed to $150 \mu \mathrm{L}$ with DMEM and it was incubated for 48 hours. After, the medium was removed from the wells, the cells were washed two times with phosphate-buffered saline (PBS) $1 \mathrm{x}$, and $50 \mu \mathrm{L}$ of a mixture of $0.4 \mathrm{mg} / \mathrm{mL} 5$-bromo-4-chloro-3-indolyl $\beta$-D-galactopyranoside (X-gal, Sigma-Aldrich, USA) in a solution of $5 \mathrm{mM}$ potassium ferricyanide (Meyer, Mexico), $5 \mathrm{mM}$ potassium ferrocyanide (Meyer, Mexico), and $2 \mathrm{mM}$ magnesium chloride (Meyer, Mexico) dissolved in PBS 1x was added; the cells were incubated for 24 hours.

For the transfection study, the pSV- $\beta$-Gal bounded to the vehicle (the AuNPs) allows the cells to produce the $\beta$-galactosidase enzyme [26]. The activity of this enzyme in histochemistry with X-gal yields insoluble blue compounds similar to indigo as a result of enzyme-catalyzed hydrolysis [27]. The transfected cells were stained for the enzymatic activity of $\beta$-galactosidase expression of pSV- $\beta$-Gal, and the cells were counted in three different fields by an image processing software developed in Matlab ${ }^{\circledR}$.

On the other hand, the pIRES2-EGFP after the expression produces into the cell a green-fluorescent protein which stains the transfected cells [28]; the transfection efficiency was evaluated by using the fluorescence microscope Carl Zeiss Axio Vert.A1.

In addition, $30 \mu \mathrm{L}$ of a lipofectamine reagent (Sigma, USA) bounded to the plasmid was used as a positive control.

2.8. Cell Uptake Study of the Atorvastatin. The cells were incubated with the same conditions, and they interacted with $50 \mu \mathrm{L}$ of the Au-PEG-At for 24 hours; then, they were washed with PBS and observed with the fluorescence microscope.

Gold nanoparticles loaded with atorvastatin, which enter into the cells, stain the cytoplasm due to the atorvastatin molecule which presents fluorescence at $310 \mathrm{~nm}$ (excitation and $385 \mathrm{~nm}$ emission). The cell uptake efficiency was evaluated with the micrographs from 3 different fields by using the image processing software developed in $\mathrm{Matlab}^{\circledR}$. In addition, $50 \mu \mathrm{L}$ of $1 \mathrm{mg} / \mathrm{mL}$ free atorvastatin solution was used as a control.

2.9. Cytotoxicity Test. The cell viability assay was performed in order to know the toxicity of the gold nanoparticles to the cells. The cells were incubated with $20 \mu \mathrm{L}$ of gold nanocomposites and $30 \mu \mathrm{L}$ of culture medium during 2 hours; subsequently, they were washed two times with PBS; then, $20 \mu \mathrm{L}$ of $0.2 \%$ trypan blue (Sigma, USA) was added, and finally, after 30 minutes, two more PBS washes were made. The cells stained by the dye (dead cells) were counted by the image processing software in three different fields. In this case, $30 \mu \mathrm{L}$ of lipofectamine was used also as a control since it is known that this reagent is cytotoxic.

\section{Results}

3.1. Gold Nanoparticle Characterization. The absorption spectra of the AuNPs and AuNP-PEG showed a change in the absorption band at longer wavelengths in the spectrum of the PEGylated gold nanoparticles; the optical changes indicate modifications in the nanoparticle surface, and it is attributed to the functionalization of the AuNPs with the polymer. Figure 3(a) shows the UV-visible spectra of the $40 \mathrm{~nm}$ gold nanoparticles uncoated and PEGylated.

In addition, the stability of AuNPs as a function of $\mathrm{pH}$ was evaluated by varying the $\mathrm{pH}$ from 3 to 10 . It was found that there are not significant differences between the surface plasmon resonance (SPR) bands of the PEGylated gold nanoparticles coated at different $\mathrm{pH}$. However, the uncoated gold nanoparticles showed changes in the absorption spectra at a $\mathrm{pH}$ of 3 and less significance at 10 (Figures 3(b) and 3(c)); this red shift is due to the nanoparticle aggregation. These results confirm that polymer coating improves the stability of the nanoparticles, avoiding the aggregation at different $\mathrm{pH}$ conditions; this was also reported by Khutale and Casey [24] who used PEGylated gold nanoparticles as a doxorubicin release system. Stability tests could be used to show the behavior of nanoparticles in colloidal suspension at different $\mathrm{pH}$ conditions and salt environment, among other similar physiological conditions. For this reason, it is necessary to find coatings which improve the stability of the colloids at different environments; in this case, it was showed that $\mathrm{SH}$ PEG- $\mathrm{NH}_{2}(2 \mathrm{KDa})$ coating on gold nanoparticles could be useful for this purpose.

Transmission electron micrographs showed the spherical shape of the synthesized gold nanoparticles and the size distribution of the gold nanoparticles synthesized with $\mathrm{CTAB}$ (diameter: $20 \pm 5 \mathrm{~nm}$ ) in Figure 4(a) and sodium borohydride (diameter: $40 \pm 5 \mathrm{~nm}$ ) in Figure 4(b). In addition, Figure 4(c) shows the $20 \mathrm{~nm}$ PEGylated gold nanoparticles, a layer which coats the AuNPs can be observed, and this is attributed to the PEG coating.

Furthermore, it was obtained that there is a change in the $Z$ potential between the nanoparticles coated and uncoated with PEG (Figure 5(a)); this is because the surface amine group of the $\mathrm{SH}-\mathrm{PEG}-\mathrm{NH}_{2}$ provides positive charges to the gold nanoparticles which increases the $Z$ potential in both cases. The $40 \mathrm{~nm}$ uncoated gold nanoparticles presented negative potential due to the carboxyl groups of the citrate which coated them; in contrast, the $20 \mathrm{~nm}$ gold nanoparticles showed positive $Z$ potential due to the CTAB, which is a cationic surfactant which promoted the growth of the seed solution, and capped the gold with positive charges. In addition, the hydrodynamic diameter of the nanoparticles increases in $37 \%$ and $28 \%$ due to the PEG which coats the synthetized gold nanoparticles (Figure 5(b)). On the other hand, the obtained averaged polydispersity indexes (PDI) were 0.634 for AuNPs $(20 \mathrm{~nm})$ and 0.253 for AuNP-PEG $(20 \mathrm{~nm})$ and 0.389 for AuNPs $(40 \mathrm{~nm})$ and 0.172 for AuNPPEG $(40 \mathrm{~nm})$. These PDI values validate the measurements of the hydrodynamic diameter; furthermore, they show that the PEGylation decreases the PDI.

3.2. Cellular Transfection and Cytotoxicity. The electropherogram showed that free pDNA does not present retardation in the gel (Figure 6, lane 1 with $400 \mathrm{ng}$ of free pDNA and 2 with $200 \mathrm{ng}$ ); however, lanes 4 to 6 , where there is interaction 

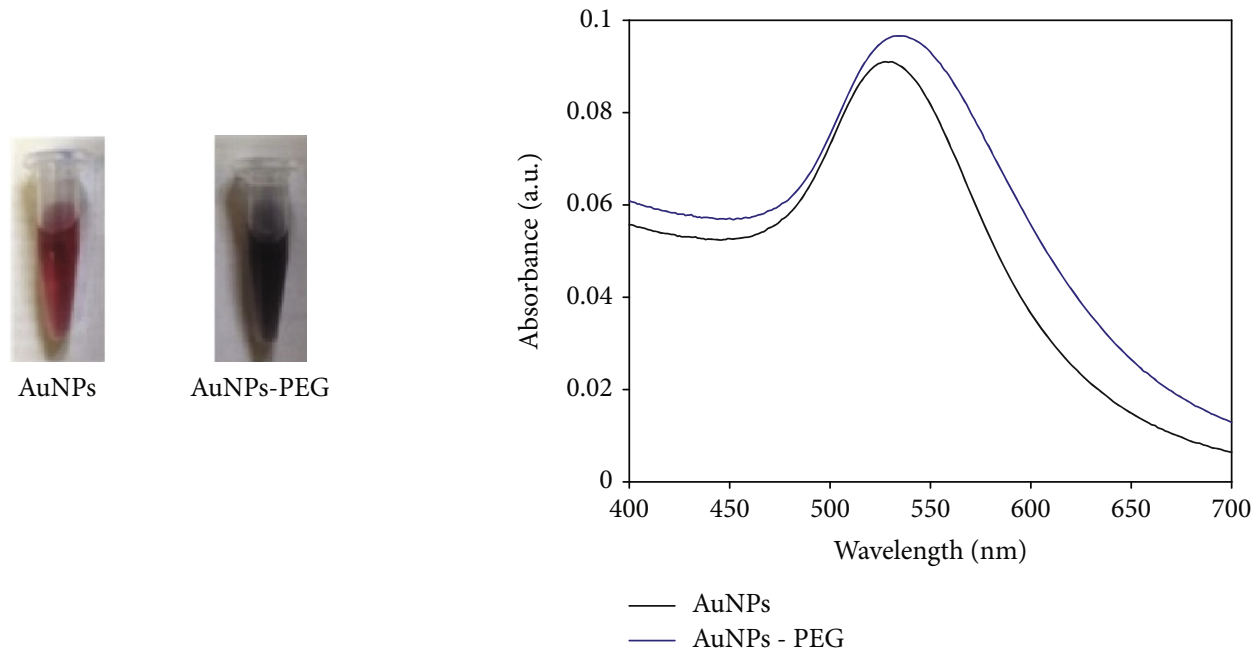

(a)

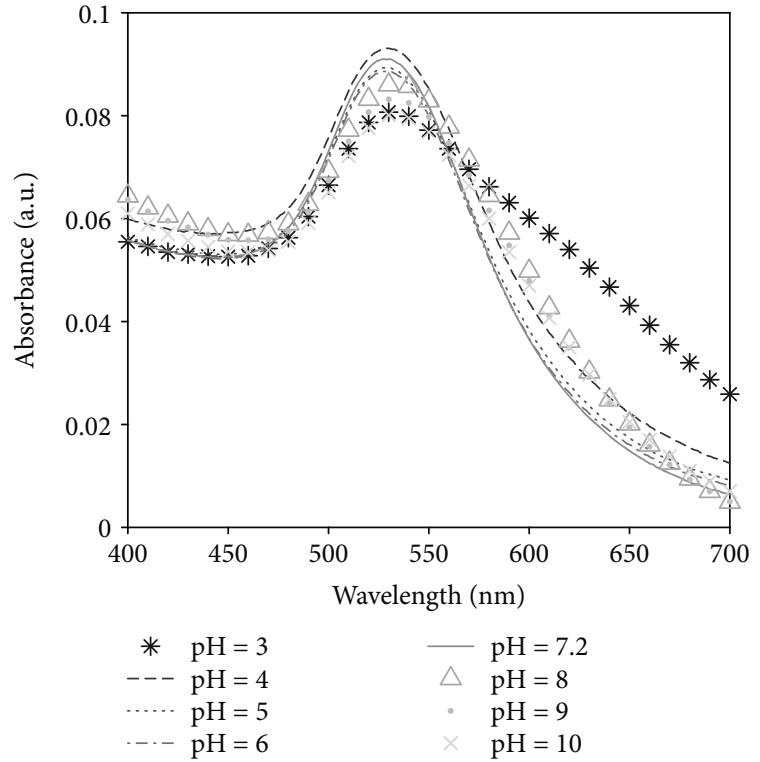

(b)

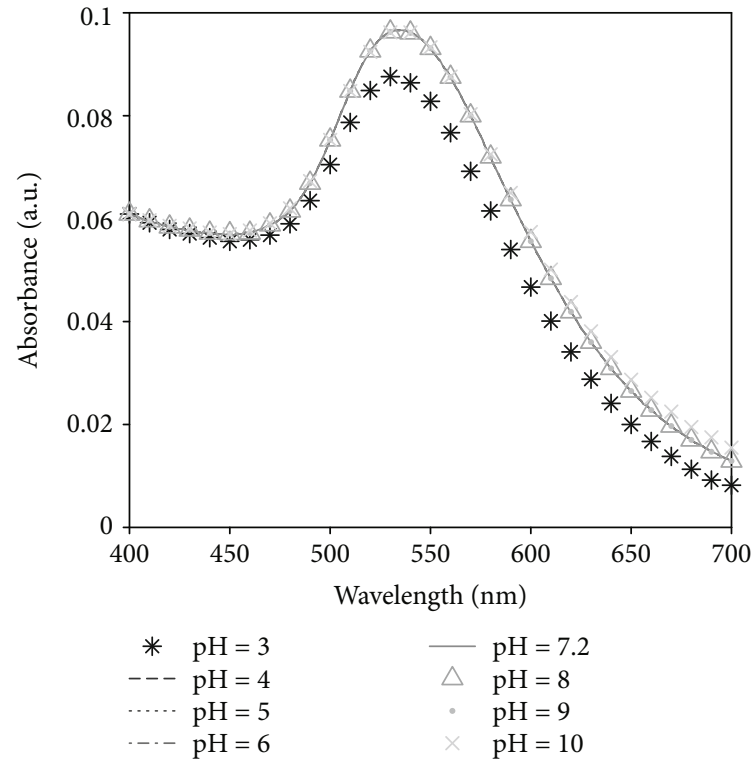

(c)

FIGURE 3: Optical characterization of the gold nanoparticles and stability test. (a) UV-visible absorption spectra of $40 \mathrm{~nm}$ AuNPs and AuNPPEG. (b) UV-vis absorption spectra of AuNPs and (c) AuNP-PEG at different pH.

between pDNA and AuNPs, present a delay. In contrast, the $40 \mathrm{~nm}$ uncoated gold nanoparticles in lane 3 did not show interaction with the DNA; therefore, the plasmid do not show delay in the gel; this is explained due to the fact that the surface potential is negative which results in a repulsion with the negative charge from DNA. On the other hand, lane 7 shows the interaction of the AuNPs with 400 ng of pDNA; the apparition of bands of the DNA was observed which did not bound to the gold nanoparticles due to the fact that they are saturated and cannot hold all of this DNA amount; i.e., it is the limit quantity of pDNA that can be bounded to the AuNPs.

Gel retardation assays allow to know the amount of DNA which could be retained by the nanoparticles, and this is due to the interaction between positive surface charges on the particle and negative charges from DNA. The most common synthesis of gold nanoparticles is by using sodium citrate or borohydride as reducing agents; however, it produces negatively charged gold nanoparticles. Hence, polymer coating is important for bounding DNA to AuNPs. For instance, Lazarus and Singh [29] used polyethylenimine (PEI) which provides positive charges to the nanoparticles, due to the presence of many amine groups in the chain, and they showed by means of electrophoresis the interaction between pCMV-luc DNA and $76 \mathrm{~nm}$ AuNPs at different mass ratios. In addition, Ahn et al. [26] found the optimal charge ratio of copolymers (PEI and PEG) for DNA delivery by using gel retardation assay as well.

Figure 7 shows a micrograph of the pSV- $\beta$-Gal transfection study of HEK 293 cells using lipofectamine and the AuNP-PEG-pDNA nanoparticles of 20 and $40 \mathrm{~nm}$ in diameter as vectors. The transfection study (Figure 7(a)) demonstrated 


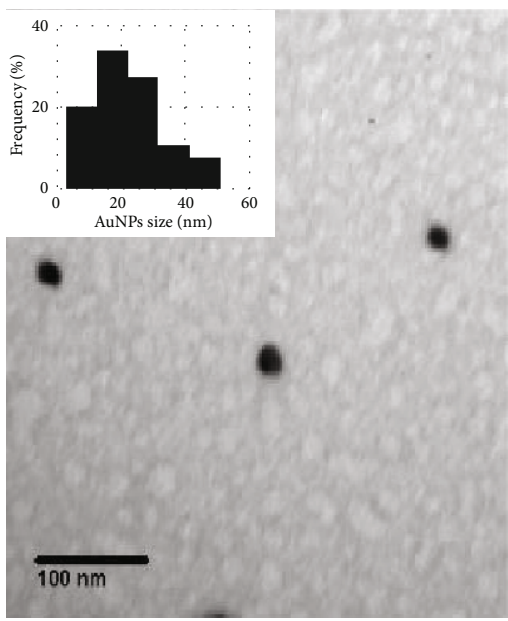

(a)

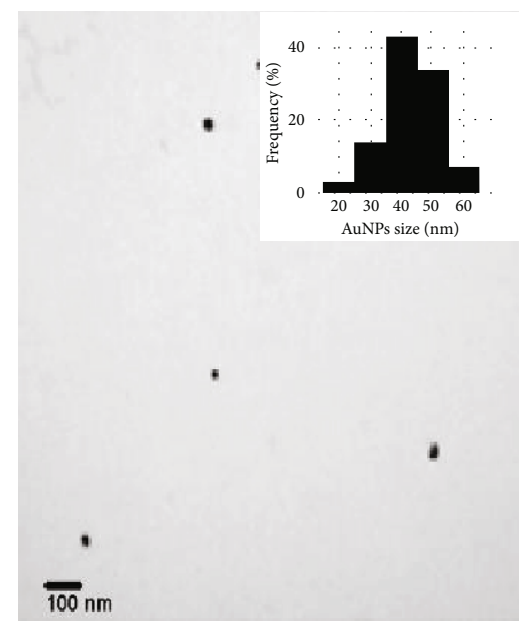

(b)

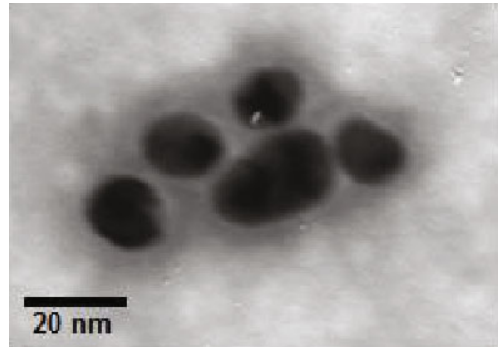

(c)

Figure 4: Transmission electron micrographs of AuNPs. (a) $20 \mathrm{~nm}$ gold nanoparticles, (b) $40 \mathrm{~nm}$ gold nanoparticles, and (c) gold nanoparticles coated with PEG contrasted by phosphotungstic acid.

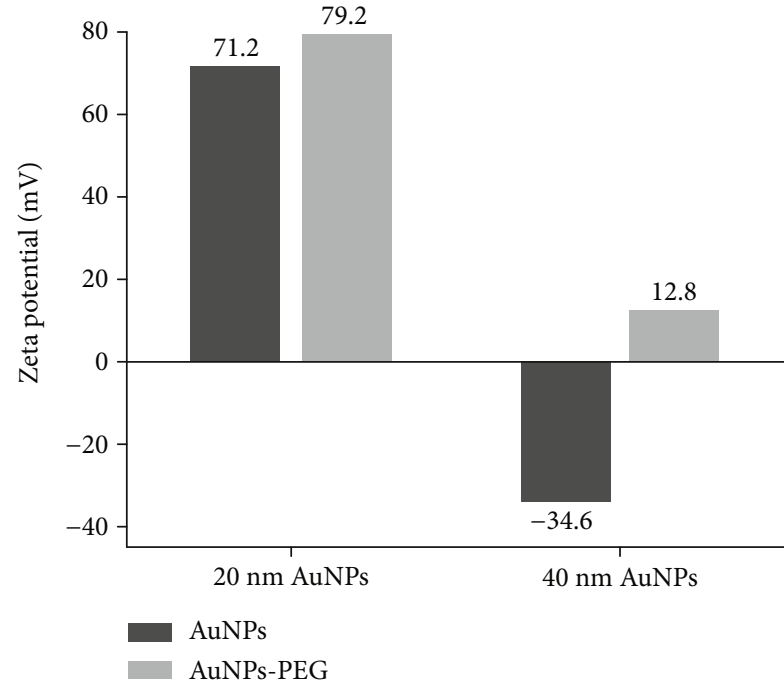

(a)

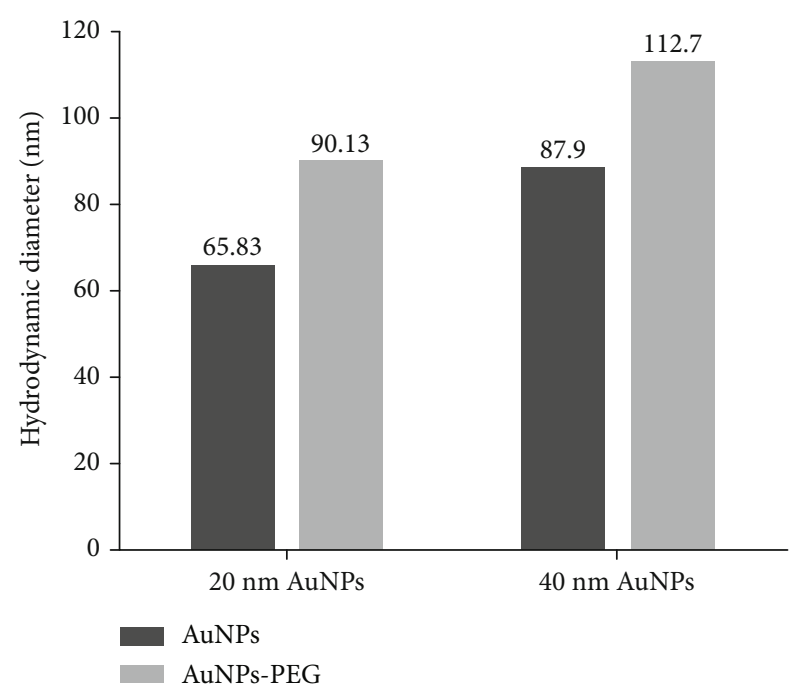

(b)

Figure 5: DLS and $Z$ potential analysis of AuNPs and AuNP-PEG. (a) $Z$ potential and (b) hydrodynamic diameter.

that the lipofectamine and $20 \mathrm{~nm}$ AuNP-PEG (Figure 7(b)) enter into the cells with the pDNA and it allows the expression of the plasmid in which blue stains the cell due to the blue molecule produced by the metabolism of the X-gal substrate. In addition, Figure 7 (c) shows the cell transfection of the AuNPs of $40 \mathrm{~nm}$ in diameter.

Figure 8(a) shows a micrograph of the cells incubated with the AuNP-PEG-pIRES2-EGFP nanoparticles. The transfection study demonstrated that the AuNP-PEG enter into the cells with the pDNA and it allows the expression of the plasmid which stains the cell due to the transcription of the green fluorescent protein [28].

On the other hand, Figure 8(b) shows the cellular uptake of the atorvastatin using AuNP-PEG particles as carriers. It can be observed that the atorvastatin which enters into the cells with the vehicle helps stain the cytoplasm; however, it was demonstrated that the free atorvastatin do not enter into the cells and then was removed by the PBS; hence, the micrograph did not show fluorescence with the UV lamp.

Furthermore, the cytotoxicity test with trypan blue showed that the synthetized gold nanoparticles have a low toxicity effect to this cell culture, and with the conditions described, the micrograph obtained by the cytotoxicity test (Figure 9) shows a higher proportion of living cells than dead cells (blue-stained cells).

Finally, Figure 10 summarizes the results obtained of the cellular transfection efficiency, drug cell uptake, and cytotoxicity. Lipofectamine showed the highest amount of cellular transfection of both plasmids, but it is cytotoxic $(46.64 \%$ of dead cells). However, the PEG-coated gold nanoparticles synthetized by both methods showed $<10 \%$ of dead cells (6.2\% and $4.1 \%$, respectively) and the transfection efficiency $>45 \%$. It can be also observed that the results of transfection efficiency of the two plasmids are similar; however, in the 


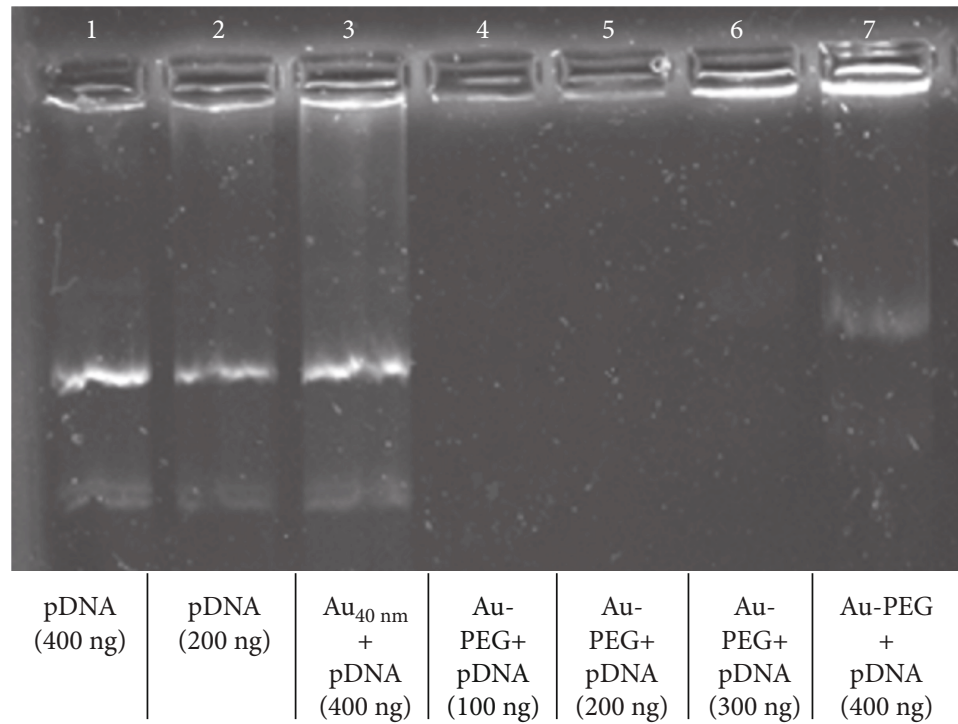

FIGURE 6: Electropherogram of pSV- $\beta$-Gal and AuNP interaction. In lanes 1 and 2, the shift of different quantities of pDNA can be observed. Lane 3 contained the uncoated $40 \mathrm{~nm}$ gold nanoparticles and $400 \mathrm{ng}$ of pDNA; the negative charges in both did not allow the interaction between them. Lanes 4 to 7 contained different quantities of pDNA bind to the PEGylated gold nanoparticles.

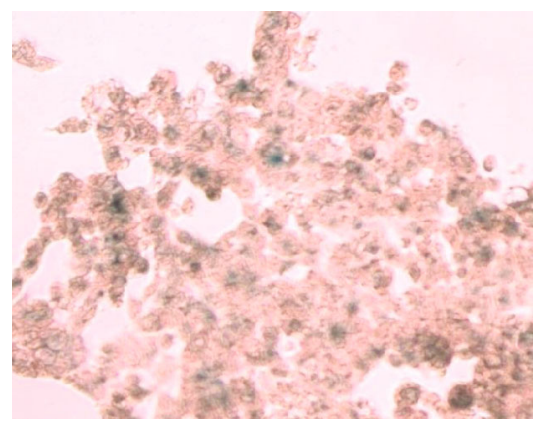

(a)

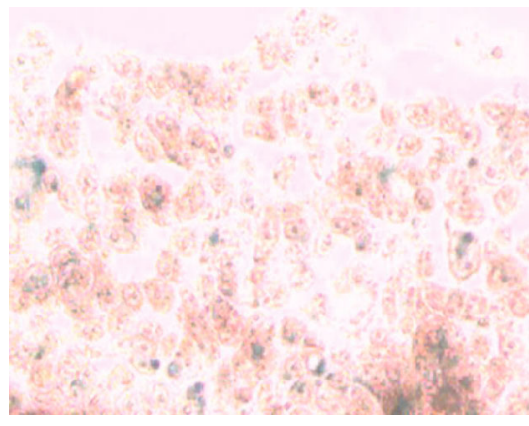

(b)

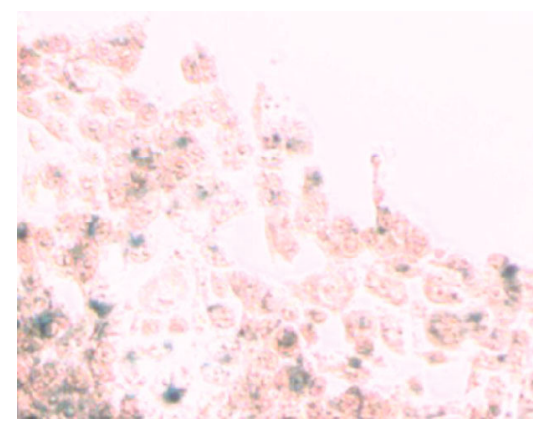

(c)

FIGURE 7: Micrograph of cells transfected with pSV- $\beta$-Gal using (a) lipofectamine and (b) $20 \mathrm{~nm}$ and (b) $40 \mathrm{~nm}$ gold nanoparticles as vectors.

three cases, the transfection of pIRES2-EGFP is greater than the pSV- $\beta$-Gal. In addition, smaller gold nanoparticles $(20 \mathrm{~nm})$ provide greater transfection efficiency in both kinds of plasmids, as expected, but they have a greater cytotoxicity effect than the $40 \mathrm{~nm}$, and this was also expected due to some publications that agree that the smaller nanoparticles have a greater cytotoxic effect [11].

\section{Discussion}

Transfection efficiencies of pSV- $\beta$-Gal obtained in this work are comparable to those reported by González et al. [30] who used gold nanoparticles capped with different types of chitosan as pSV- $\beta$-Gal delivery systems. Chitosan provides more positive charges to the nanoparticles than the SH-PEG$\mathrm{NH}_{2}$, due to the fact that the chitosan has an amine group in each monomer of the chain; therefore, the chitosan could retain more DNA and the obtained transfection efficiencies for some types of chitosan are higher than the those reported in this work; however, in some cases, the AuNP-chitosan were cytotoxic.
Results of pIRES2-EGFP transfection efficiency obtained in this work are comparable to those reported by Liu et al. [31] who used a modification of the vector pIRES2-EGFP by using liposomes as vehicles to evaluate transfection by means of fluorescence microscopy. However, transfection efficiencies of AuNP-PEG evaluated in the present work are slightly higher than those the liposomes.

Furthermore, the obtained transfection efficiency of these plasmids by using AuNP-PEG is higher than the efficiency obtained from many methods used for gene therapy; this shows that the gold nanoparticles coated with PEG could be considered promising DNA vehicles for many medical proposes, for instance, cancer therapy.

On the other hand, the drug cellular uptake by using the gold nanoparticles as carriers is greater in the larger nanoparticles, in contrast with the transfection results obtained; however, it was demonstrated that the free atorvastatin cannot enter into the cells ( $0 \%$ of cell uptake) which besides confirms that both types of AuNPs are effectively performing the role of drug carriers $(69.39 \%$ and $75.12 \%$ of drug cell uptake, respectively). Cellular uptake studies of fluorescent drugs 


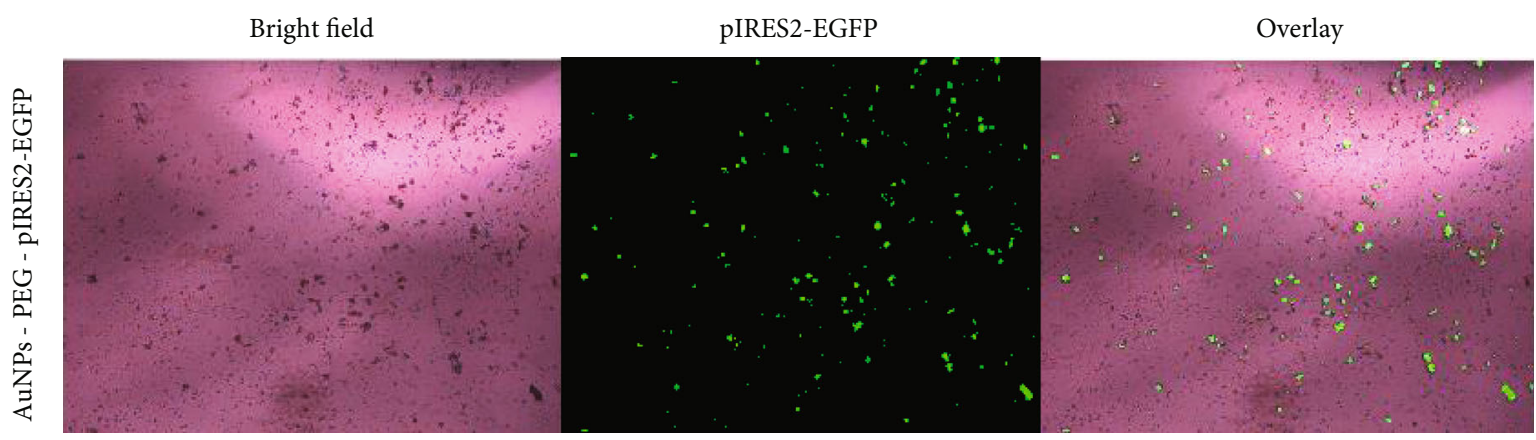

(a)

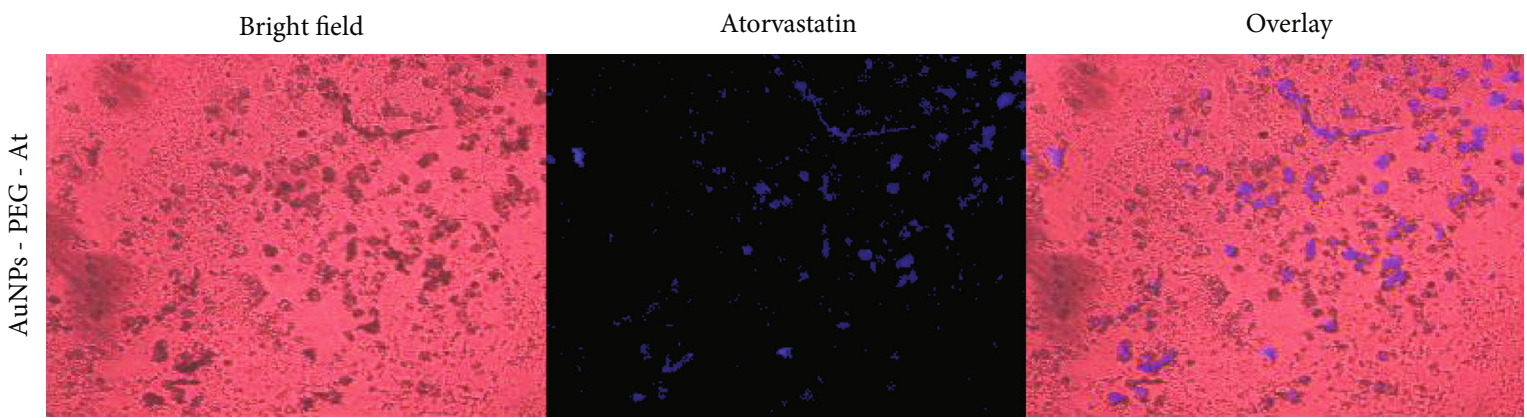

(b)

FIGURE 8: Micrograph of the fluorescence stain cell produces for (a) the activity of the pIRES2-EGFP and the (b) atorvastatin uptake by the cells using PEGylated gold nanoparticles as vehicles.

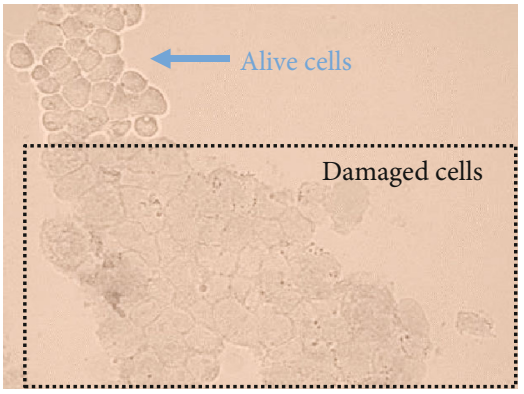

(a)

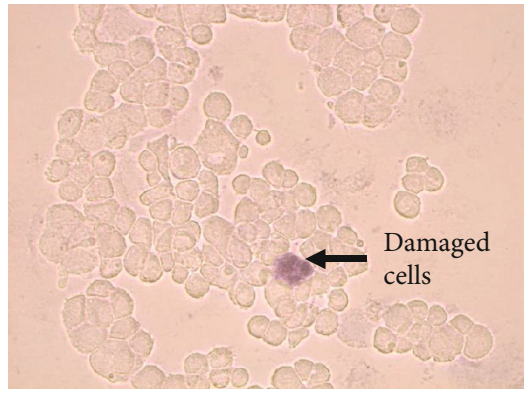

(b)

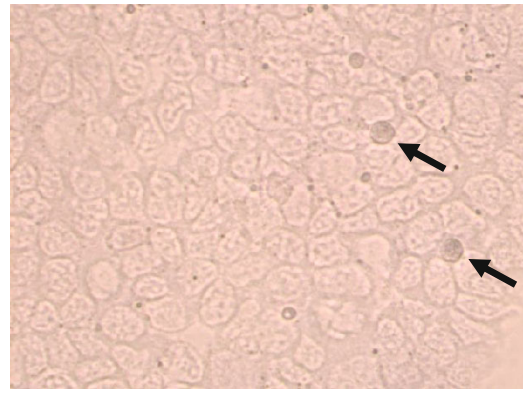

(c)

Figure 9: Micrograph of the cytotoxicity test of HEK293 cells. Using (a) atorvastatin and (b) $20 \mathrm{~nm}$ and (c) $40 \mathrm{~nm}$ PEGylated gold nanoparticles. The black arrows and black rectangle show the damaged or dead cells, and the blue arrow show the alive cells.

are semiquantitative methods which allow to know if the carrier molecule is transporting a drug into the cell [32]. Currently, nanocarriers have been used due to the physical and chemical advantages that they have. For instance, Khutale and Casey [24] proposed PEGylated gold nanoparticles as doxorubicin carriers and they showed that these produce higher cellular uptake at short time exposures than the free doxorubicin.

In addition, the low cytotoxicity and drug release efficiency obtained promises that these nanoparticles could be used in several applications in medical treatments as drug delivery systems. These results complement those obtained by Patra et al. [33] who showed that gold nanoparticles synthetized with $\mathrm{CTAB}$ and coated with PEG are not toxic to Hep2G and BHK21 cell lines but it produces cytotoxicity to A549 cells. In general, gold nanoparticle toxicity depends on the concentration and cell type, but there are many studies which conclude that AuNPs do not have toxicity effects (see Reference [34] and the references within).

\section{Conclusions}

Gold nanoparticles of two different sizes (20 and $40 \mathrm{~nm}$ ) were synthetized, the gold nanoparticles were coated with PEG, and it was shown that this coat improves the stability of the gold nanoparticles at different $\mathrm{pH}$; besides, two different plasmid DNAs (pSV- $\beta$-Gal and pIRES2-EGFP) were bounded to the nanoparticles; the interaction between the nanoparticles and the plasmid (up to $300 \mathrm{ng}$ ) was demonstrated by agarose gel electrophoresis; this confirms that the synthetized PEGylated gold nanoparticles could be used as vehicles of these plasmids. 


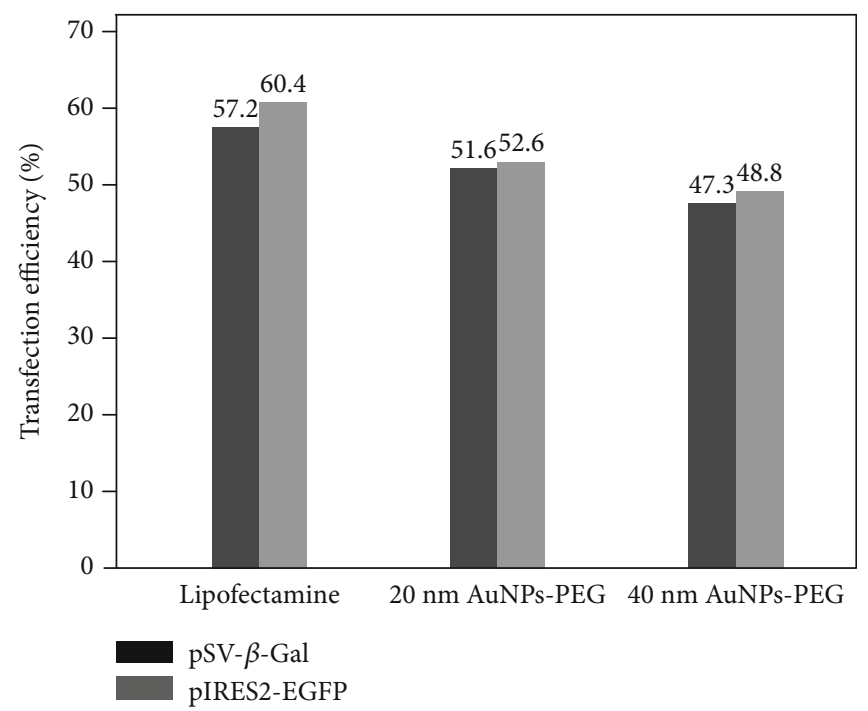

(a)

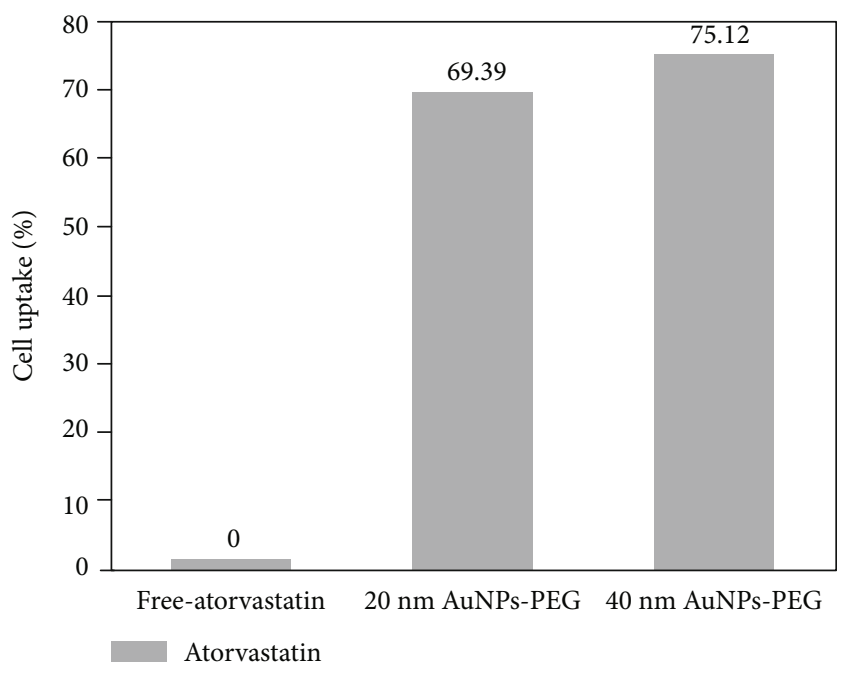

(b)

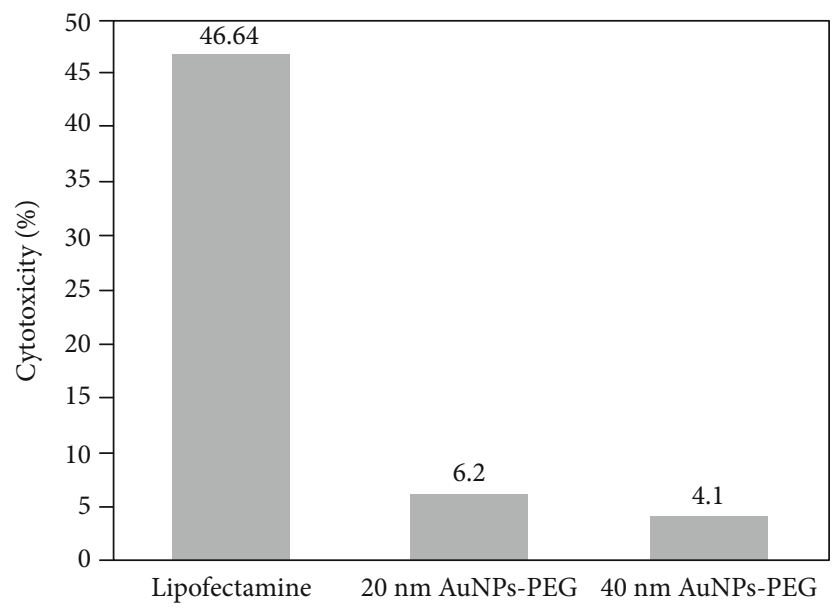

(c)

FIGURE 10: Summary of the results obtained. (a) Transfection efficiency of lipofectamine and 20 and 40 nm AuNP-PEG, (b) atorvastatin cell uptake using the gold nanoparticles as nanocarriers, and (c) cytotoxicity test of lipofectamine and AuNP-PEG.

The results of the transfection study between both plasmids were similar, and it was showed that 20 and $40 \mathrm{~nm}$ PEGylated gold nanoparticles presented a transfection efficiency comparable with the lipofectamine but the main difference is that the cytotoxicity effect is lower if the PEGcoated gold nanoparticles are employed as vehicles compared with the lipofectamine.

In addition, it was shown that the synthetized AuNPPEG worked as carriers of the atorvastatin and the drug uptake obtained was $\approx 70 \%$ which demonstrates that these nanoparticles are suitable to be used as drug nanocarriers.

These results show that gold nanoparticles coated with PEG have a great potential use in several medical applications, particularly in gene therapy and drug delivery systems.

\section{Abbreviations}

PEG:

AuNPs:

pDNA:
AuNP-PEG: PEGylated gold nanoparticles

AuNP-PEG-pDNA: PEGylated gold nanoparticles loaded with plasmid DNA

AuNP-PEG-At: $\quad$ PEGylated gold nanoparticles loaded with atorvastatin

CTAB:

SPR:

TEM:

DMEM:

PEI:

\section{Data Availability}

The micrographs and gold nanoparticle characterization data used to support the findings of this study are available from the corresponding author upon request.

\section{Conflicts of Interest}

The authors declare that they have no competing interests. 


\section{Acknowledgments}

The authors acknowledge the Instituto Politécnico Nacional and the Secretaría de Investigación y Posgrado (SIP) for the economic support of this work and the integrants of the photothermal techniques and gene therapy laboratories for the support. Also, JAZ-J acknowledge the Consejo Nacional de Ciencia y Tecnología (CONACyT) for the PhD scholarship.

\section{References}

[1] B. Klebowski, J. Depciuch, M. Parlinska-Wojtan, and J. Baran, "Applications of noble metal-based nanoparticles in medicine," International Journal of Molecular Sciences, vol. 19, no. 12, p. 4031, 2018

[2] G. Ferro-Flores, B. Ocampo-García, C. Santos-Cuevas, E. Morales-Avila, and E. Azorín-Vega, "Multifunctional radiolabeled nanoparticles for targeted therapy," Current Medicinal Chemistry, vol. 21, no. 1, pp. 124-138, 2013.

[3] M. Prabaharan, J. J. Grailer, S. Pilla, D. A. Steeber, and S. Gong, "Gold nanoparticles with a monolayer of doxorubicinconjugated amphiphilic block copolymer for tumor-targeted drug delivery," Biomaterials, vol. 30, no. 30, pp. 6065-6075, 2009.

[4] C. S. Lee, H. Kim, J. Yu et al., "Doxorubicin-loaded oligonucleotide conjugated gold nanoparticles: a promising in vivo drug delivery system for colorectal cancer therapy," European Journal of Medicinal Chemistry, vol. 142, pp. 416-423, 2017.

[5] K. Sztandera, M. Gorzkiewicz, and B. Klajnert-Maculewicz, "Gold nanoparticles in cancer treatment," Molecular Pharmaceutics, vol. 16, no. 1, pp. 1-23, 2019.

[6] V. Melani, M. B. Haddada, H. Moustaoui et al., "Pegylated doxorubicin gold complex: from nanovector to potential intercalant agent for biosensor applications," Frontiers in Laboratory Medicine, vol. 1, no. 3, pp. 114-121, 2017.

[7] N. A. Hanan, H. I. Chiu, M. R. Ramachandran et al., "Cytotoxicity of plant-mediated synthesis of metallic nanoparticles: a systematic review," International Journal of Molecular Sciences, vol. 19, no. 6, article 1725, 2018.

[8] K. Brzóska, I. Grądzka, and M. Kruszewski, "Impact of silver, gold, and iron oxide nanoparticles on cellular response to tumor necrosis factor," Toxicology and Applied Pharmacology, vol. 356, pp. 140-150, 2018.

[9] B. D. Chithrani and W. C. W. Chan, "Elucidating the mechanism of cellular uptake and removal of protein-coated gold nanoparticles of different sizes and shapes," Nano Letters, vol. 7, no. 6, pp. 1542-1550, 2007.

[10] J. Lin, H. Zhang, Z. Chen, and Y. Zheng, "Penetration of lipid membranes by gold nanoparticles: insights into cellular uptake, cytotoxicity, and their relationship," ACS Nano, vol. 4, no. 9, pp. 5421-5429, 2010.

[11] C. Louis and O. Pluchery, Gold Nanoparticles for Physics, Chemistry and Biology, Imperial College Press, Paris, France, 1st edition, 2012.

[12] B. D. Chithrani, A. A. Ghazani, and W. C. W. Chan, "Determining the size and shape dependence of gold nanoparticle uptake into mammalian cells," Nano Letters, vol. 6, no. 4, pp. 662-668, 2006.

[13] W. Weecharangsan, P. Opanasopit, T. Ngawhirunpat, T. Rojanarata, and A. Apirakaramwong, "Chitosan lactate as a nonviral gene delivery vector in COS-1 cells," AAPS PharmSciTech, vol. 7, no. 3, pp. E74-E79, 2006.

[14] K. C. Remant Bahadur, S. Aryal, S. R. Bhattarai, N. Bhattarai, C. H. Kim, and H. Y. Kim, "Stabilization of gold nanoparticles by hydrophobically-modified polycations," Journal of Biomaterials Science, Polymer Edition, vol. 17, no. 5, pp. 579-589, 2006.

[15] Y. Chang, E. Lee, J. Kim, Y. W. Kwon, Y. Kwon, and J. Kim, "Efficient in vivo direct conversion of fibroblasts into cardiomyocytes using a nanoparticle-based gene carrier," Biomaterials, vol. 192, pp. 500-509, 2019.

[16] M. Ibáñez, R. Santiago, C. Wong, I. Baeza, P. Gariglio, and P. Chávez, "Spermidine-condensed DNA and cone-shaped lipids improve delivery and expression of exogenous DNA transfer by liposomes," Biochemistry and Cell Biology, vol. 74, no. 5, pp. 633-643, 1996.

[17] P. C. Ross, M. L. Hensen, R. Supabphol, and S. W. Hui, "Multilamellar cationic liposomes are efficient vectors for in vitro gene transfer in serum," Journal of Liposome Research, vol. 8, no. 4, pp. 499-520, 1998.

[18] G. G. Lazarus and M. Singh, "In vitro cytotoxic activity and transfection efficiency of polyethyleneimine functionalized gold nanoparticles," Colloids and Surfaces B: Biointerfaces, vol. 145, pp. 906-911, 2016.

[19] H. Daraee, A. Eatemadi, E. Abbasi, S. Fekri Aval, M. Kouhi, and A. Akbarzadeh, "Application of gold nanoparticles in biomedical and drug delivery," Artificial Cells, Nanomedicine, and Biotechnology, vol. 44, no. 1, pp. 410-422, 2016.

[20] S. H. Hosseinali, Z. P. Boushehri, B. Rasti, M. Mirpour, K. Shahpasand, and M. Falahati, "Biophysical, molecular dynamics and cellular studies on the interaction of nickel oxide nanoparticles with tau proteins and neuron-like cells," International Journal of Biological Macromolecules, vol. 125, pp. 778-784, 2019.

[21] J. Turkevich, P. C. Stevenson, and J. Hillier, “A study of the nucleation and growth processes in the synthesis of colloidal gold," Discussions of the Faraday Society, vol. 11, pp. 55-75, 1951.

[22] C. J. Murphy, T. K. Sau, A. M. Gole et al., "Anisotropic metal nanoparticles: synthesis, assembly, and optical applications," The Journal of Physical Chemistry B, vol. 109, no. 29, pp. 13857-13870, 2005.

[23] C. N. Hernández Candia, S. Tafoya Martínez, and B. Gutiérrez-Medina, "A minimal optical trapping and imaging microscopy system," PLoS One, vol. 8, no. 2, 2013.

[24] G. V. Khutale and A. Casey, "Synthesis and characterization of a multifunctional gold-doxorubicin nanoparticle system for $\mathrm{pH}$ triggered intracellular anticancer drug release," European Journal of Pharmaceutics and Biopharmaceutics, vol. 119, pp. 372-380, 2017.

[25] A. L. Chen, M. A. Jackson, A. Y. Lin et al., "Changes in optical properties of plasmonic nanoparticles in cellular environments are modulated by nanoparticle PEGylation and serum conditions," Nanoscale Research Letters, vol. 11, no. 1, p. 303, 2016.

[26] C. H. Ahn, S. Y. Chae, Y. H. Bae, and S. W. Kim, "Biodegradable poly(ethylenimine) for plasmid DNA delivery," Journal of Controlled Release, vol. 80, no. 1-3, pp. 273-282, 2002.

[27] S.-F. Xu, L. Liu, M.-N. Sun, S. Zhao, Y. Fang, and Y. Tan, "Cloning, expression and activity assay of ED/EA of $\beta$-galactosidase in E. coli," Journal of Jilin University(Medicine Edition), vol. 36, pp. 40-44, 2010. 
[28] R. K. Pramod and A. Mitra, "Intratesticular injection followed by electroporation allows gene transfer in caprine spermatogenic cells," Scientific Reports, vol. 8, no. 1, article 3169, 2018.

[29] G. G. Lazarus and M. Singh, "Cationic modified gold nanoparticles show enhanced gene delivery in vitro," Nanotechnology Reviews, vol. 5, no. 5, pp. 425-434, 2016.

[30] P. Abrica-González, J. A. Zamora-Justo, A. Sotelo-López et al., "Gold nanoparticles with chitosan, N-acylated chitosan, and chitosan oligosaccharide as DNA carriers," Nanoscale Research Letters, vol. 14, no. 1, p. 258, 2019.

[31] Z. Liu, L. Hao, N. Wang et al., "Construction and identification of the recombinant hFceRI $\alpha /$ RBL-2H3 cells," Plasmid, vol. 98, pp. 31-36, 2018.

[32] R. Boscencu, G. Manda, N. Radulea et al., "Studies on the synthesis, photophysical and biological evaluation of some unsymmetrical meso-tetrasubstituted phenyl porphyrins," Molecules, vol. 22, no. 11, p. 1815, 2017.

[33] H. K. Patra, S. Banerjee, U. Chaudhuri, P. Lahiri, and A. K. Dasgupta, "Cell selective response to gold nanoparticles," Nanomedicine: Nanotechnology, Biology and Medicine, vol. 3, no. 2, pp. 111-119, 2007.

[34] A. M. Alkilany and C. J. Murphy, "Toxicity and cellular uptake of gold nanoparticles: what we have learned so far?," Journal of Nanoparticle Research, vol. 12, no. 7, pp. 2313-2333, 2010. 


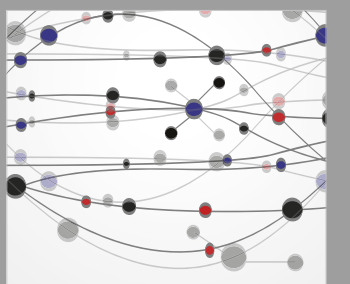

The Scientific World Journal
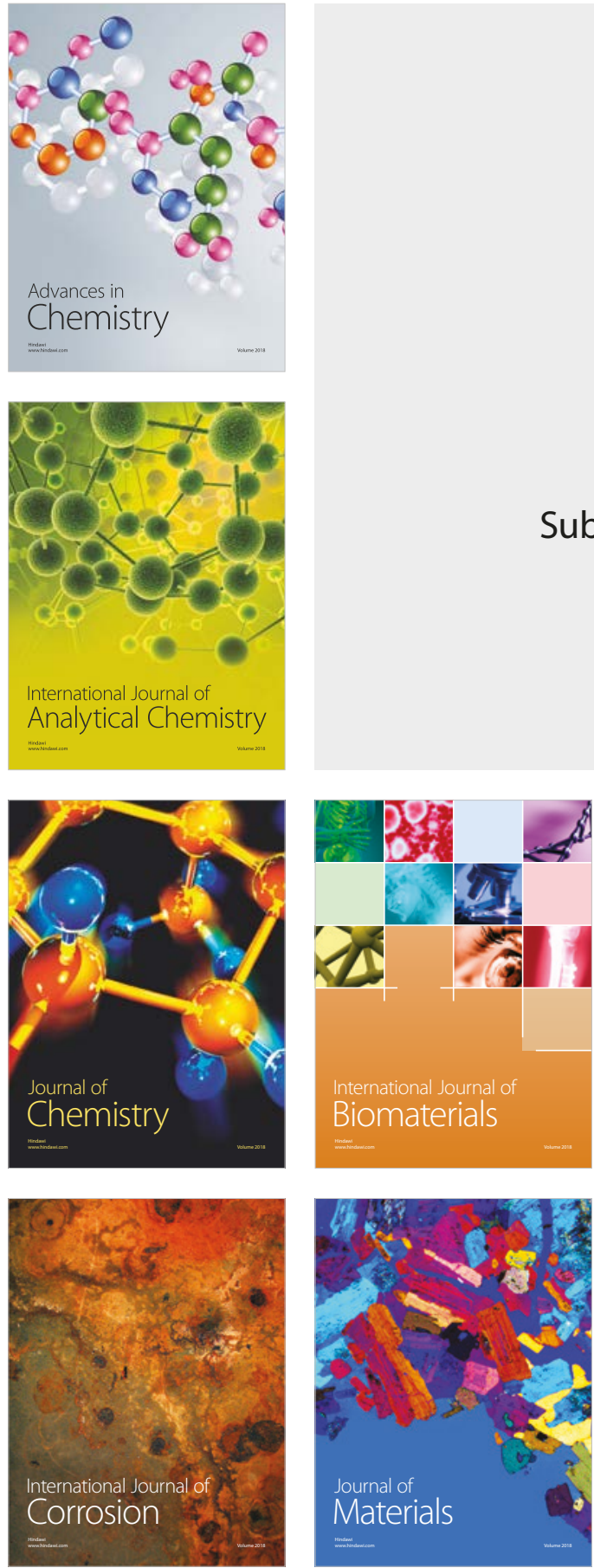

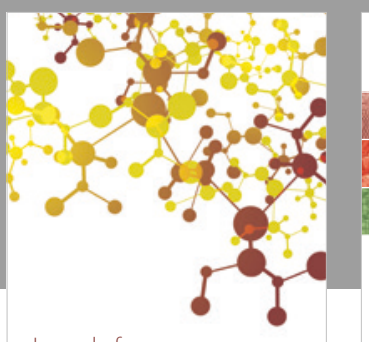

Journal of

Applied Chemistry
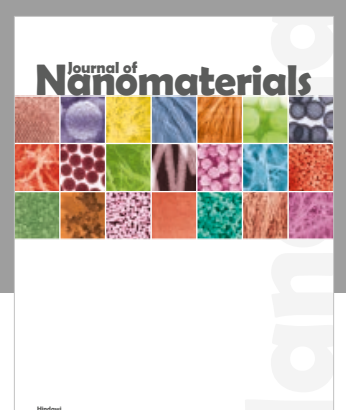

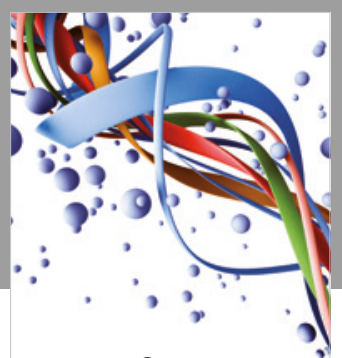

Scientifica

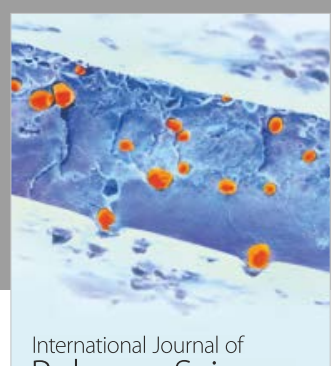

Polymer Science

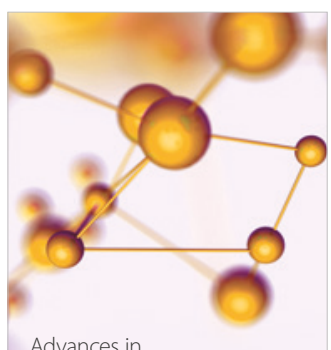

Physical Chemistry
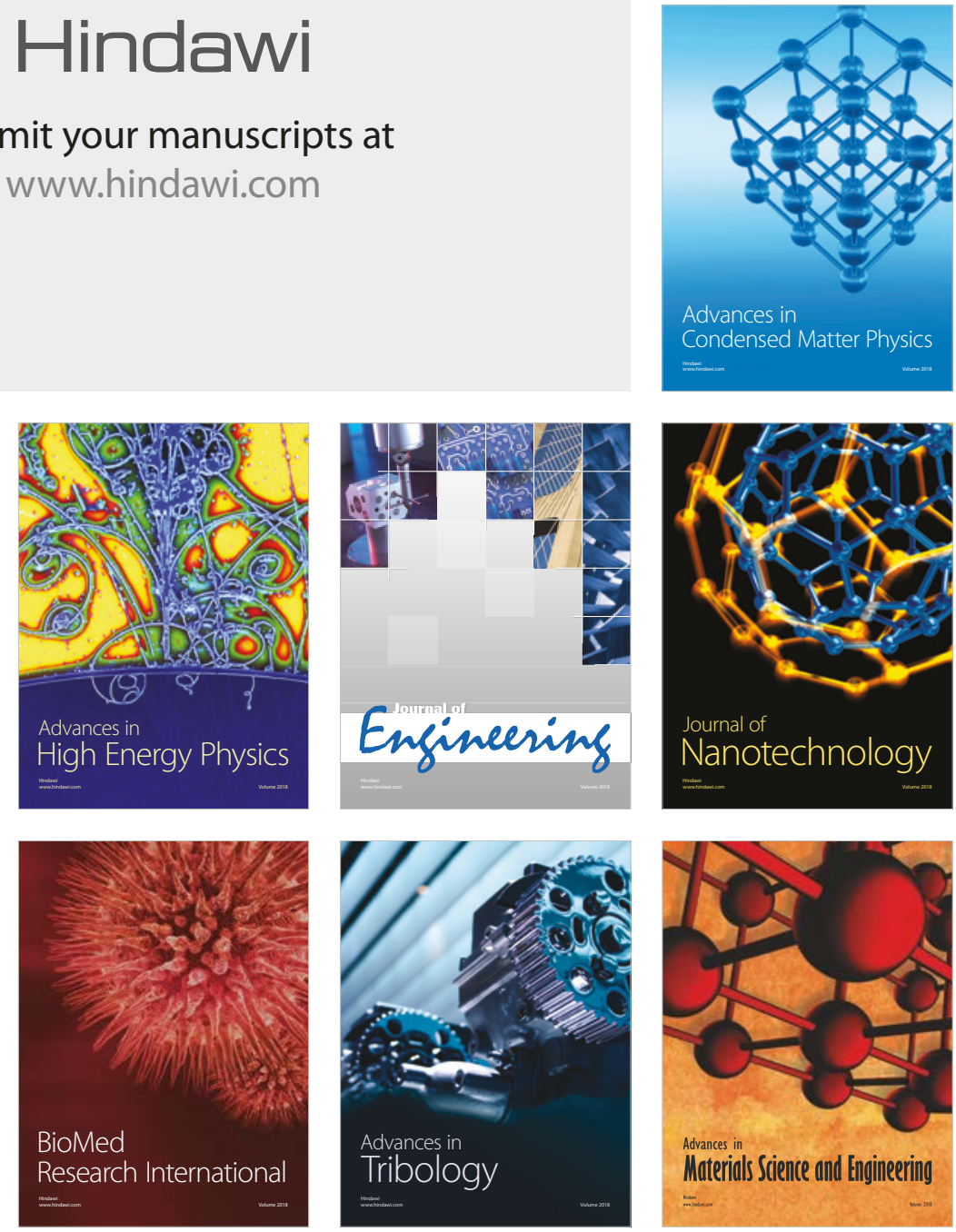